\title{
Stormy opening to hurricane season
}

The US National Hurricane Center in Miami, Florida, always uses the 1 June start date of the Atlantic hurricane season to remind coastal residents to be prepared for storms. But the lead-up to this year's season has exposed internal bickering and raised questions about whether the centre has the resources it needs.

Just days before the federal government issued a dire prediction of an above-average hurricane season - similar to the 2006 prediction (see table) - the centre's director complained very publicly about the budget he had to track and forecast those storms. Bill Proenza, who came on board as centre director early this year, criticized his bosses for spending too much money on anniversary celebrations and not enough on replacing a key satellite - the QuickScatterometer, or QuikSCAT. At the press briefing to announce hurricane predictions on 22 May, tensions ran high as Proenza shared the stage with the head of the National Oceanic and Atmospheric Administration (NOAA), retired vice-admiral Conrad Lautenbacher.

The spat reveals some long-simmering

TROUBLE AHEAD IN THE ATLANTIC?

\begin{tabular}{|l|l|l|l|}
\hline & $\begin{array}{l}\text { Storms predicted } \\
\text { in May 2006 }\end{array}$ & $\begin{array}{l}\text { Actual 2006 } \\
\text { hurricane season }\end{array}$ & $\begin{array}{l}\text { Storms predicted } \\
\text { in May 2007 }\end{array}$ \\
\hline Tropical storms & $13-16$ & 9 & $13-17$ \\
\hline Hurricanes & $8-10$ & 5 & $7-10$ \\
\hline Major hurricanes & $4-6$ & 2 & $3-5$ \\
\hline
\end{tabular}

* Winds of 178 kilometres per hour or greater.

Not including Hurricane Zeta, in January 2006, considered part of the 2005 season. disputes between the various agencies that make up NOAA. The agency was cobbled together in 1970 from a number of existing groups (the oldest being the Coast and Geodetic Survey, which dates back to 1807 and is the basis for NOAA's '200th-anniversary' celebrations this year). As often with such unions, it hasn't always been a happy one.

Proenza and some other researchers complain that NOAA is trying to usurp the identities of the individual services that make it up. The agency has, for example, proposed changing the names of the National Hurricane Center and its parent, the National Weather Service, to the NOAA Hurricane Center and the NOAA Weather Service.

Disputes about service names may sound petty, but there are bigger underlying problems. Proenza charges that NOAA spent a disproportionate $\$ 4$ million on anniversary celebrations aimed at outreach, and not enough on forecasting. NOAA's budget is roughly $\$ 4$ billion; of that, $\$ 6$ million goes to the hurricane centre. An agency spokesman disputes the outreach figure, saying it has amounted to only $\$ 1.5$ million over two years, and Lautenbacher says the centre gets enough to do its job.
"They both need more money," says James Baker, who headed NOAA between 1993 and 2001. He defends outreach, pointing out that the agency is not as well known as NASA even though its mission is arguably more critical to people's lives. "I used to say, 'fund the weather service or die," he says. "Trying to publicize and get the message out is good for both NOAA and the weather service."

NOAA's \$4-billion budget suffers particularly in comparison to NASA's \$16 billion. Whereas the space agency is tasked with building and flying research satellites for Earth observation,

NOAA is the agency in charge of turning them into long-term operational reality. In recent years, a series of reports from the National Research Council has identified problems in making smooth transitions from one to the other without loss of data in between.

Of particular concern for hurricane forecasting is the QuikSCAT satellite, launched by NASA in 1999. An instrument known as SeaWinds aboard the satellite measures the direction and speed of winds by bouncing microwaves off the ocean surface and measuring them on their return to the satellite. The resulting data are used to improve hurricane forecasts as storms gather speed and change direction.

But the satellite has passed its nominal fiveyear life, and Proenza has made a particular point of arguing for a successor. If SeaWinds

\section{Academics strike back at spurious rankings}

A call by a group of US colleges earlier this month to boycott the most influential university ranking in the United States has shone the spotlight on the problem of institutional rankings. Experts argue that these are based on dubious methodology and spurious data, yet they have huge influence. But help is at hand: European academics are putting some rigour into rankings by tackling the problem themselves.

On 5 May, Douglas Bennett, president of Earlham College in Richmond, Indiana, and 11 other college presidents asked colleagues to refuse to fill out surveys for the U.S. News \& World Report. That survey of institutions, they argued, "implies a false precision and authority that is not warranted by the data they use". Another 17 colleges have since signed up.

"All current university rankings are flawed to some extent; most, fundamentally," says Alan Gilbert, president and vice-chancellor of the University of Manchester in Britain. "But rankings are here to stay, and it is therefore worth the time and effort to get them right."

The rankings in the U.S. News \& World Report and those published by the British Times Higher Education Supplement (THES) depend heavily on surveys of thousands of experts - a system that some contest. A third popular ranking, by Jiao Tong University in Shanghai, China, is based on more quantitative measures, such as citations, numbers of Nobel prizewinners and publications in Nature and Science. But even these measures are not straightforward.

Thomson Scientific's ISI citation data are notoriously poor for use in rankings; names of institutions are spelled differently from one article to the next, and university affiliations are sometimes omitted altogether. After cleaning up ISI data on all UK papers for such effects, the Leeds-based consultancy Evidence Ltd, found the true number of papers from the University of Oxford, for example, to be $40 \%$ higher than listed by ISI, says director Jonathan Adams.

Researchers at Leiden University in the Netherlands have similarly recompiled the ISI database for 400 universities: half a million papers per year. Their system produces various rankings based on different indicators. One, for example, weights citations on the basis of their scientific field, so that a university that does well in a heavily cited field doesn't get an artificial extra boost (see table).

The German Center for Higher 


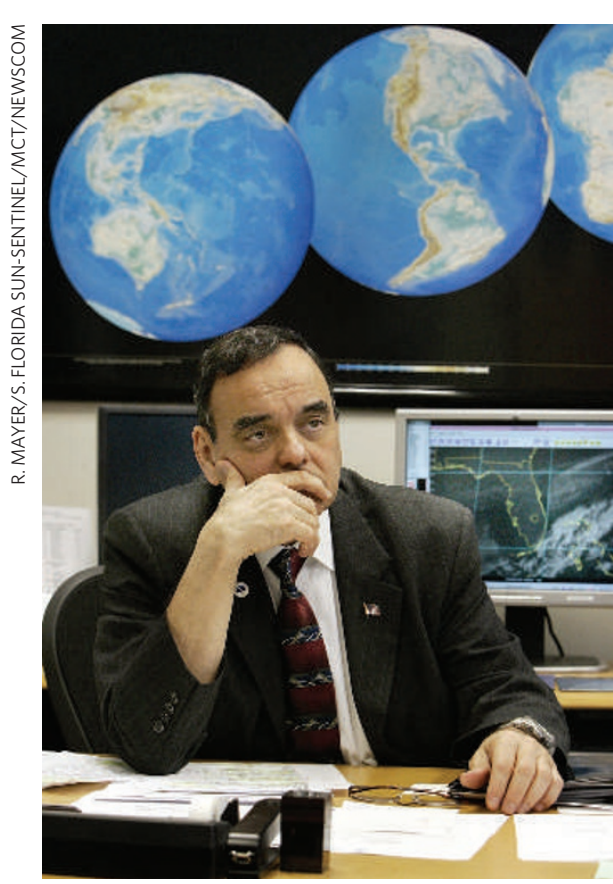

Bill Proenza wants less partying and more money for hurricane-watching satellites.

failed, he says, the accuracy of three-day hurricane forecasts would drop by about $16 \%$.

A second version of SeaWinds was launched aboard the Japanese ADEOS-II satellite in 2003, but failed just months later. Another replacement, NASA's Ocean Vector Winds mission, was cancelled early this decade.

In their place, Lautenbacher points to the joint military-civilian Coriolis satellite. It carries an instrument known as WindSat, which uses a different technique from SeaWinds for detecting wind speeds and direction rather than bouncing microwaves off the sea surface, it detects emission of microwaves from the surface.

SeaWinds has better spatial resolution than WindSat and works better under weak winds and rainy conditions, says its principal investigator, Timothy Liu of NASA's Jet Propulsion Laboratory in Pasadena, California. But WindSat does some things that SeaWinds cannot - it can provide multiple sets of data simultaneously, counters its lead scientist, Peter Gaiser of the Naval Research Laboratory in Washington DC.

Nevertheless, QuikSCAT is at least five years past the end of its nominal lifespan, and Congress has begun to get worried. Several members of Congress are pressuring NASA and NOAA for more details on what they plan to do when QuikSCAT fails.

Any potential replacement would take time to put together. QuikSCAT itself was hastily pulled together and launched just two years after a previous instrument failed without warning, but only because key parts had already been built for other purposes.

In the meantime, tensions will continue to bubble, although Lautenbacher makes the conflict seem welcome. "You have to remember that Mr Proenza just took over as the head of the hurricane centre, and he is known for being a very strong and forceful advocate for his programmes," he says. "And that's one of the reasons why we love him."

Alexandra Witze

See also the News Feature on page 522.

\section{GOOD REASONS}

Why science did well at this year's Chelsea Flower Show

1 Gold-medal-winning garden '600 Days with Bradstone' (pictured) was designed as a relaxation area - for a lonely astronaut on Mars.

2 A garden created in tribute to Linnaeus on the 300th anniversary of the naturalist's birth also scooped a gold.

3 And another gold medal went to an exhibit of plants with eco-industrial uses, including marigolds for paint, hemp for textiles - and, bizarrely, a lavender-oil fountain.

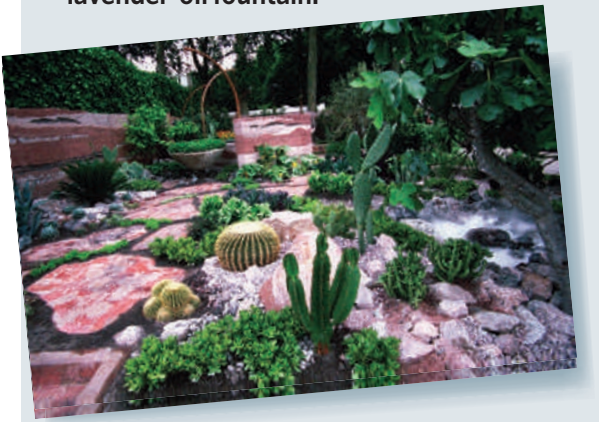

\section{SCORECARD}

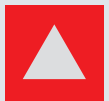

Everest's telecoms British mountaineer Rod Baber has made the first mobile telephone call from the world's highest peak.

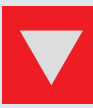

\section{US television} Bloggers have panned CBS's forthcoming sitcom The Big Bang Theory. The highly original premise features two stereotypical physicists fumbling to impress their sexy new neighbour.

\section{NUMBER CRUNCH}

300 kilometres per hour is the top speed of Japan's new fleet of iconic bullet trains - the same top speed as the old ones.

$19 \%$ is the energy saving promised by the new trains, which will run on far less electricity than their predecessors.

15 centimetres is the width of the arm-rests in first class, proving that going green doesn't always mean skimping on comfort.

Sources: Royal Horticultural Society, AFP, BBC, scienceblogs.com

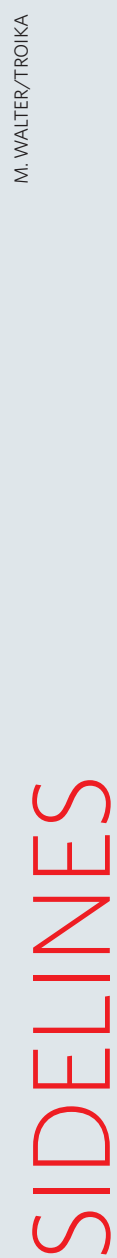

outcomes, for example. With
European Union support, the $\mathrm{CHE}$ is expanding the system to cover all Europe. Adams says that more complex systems such as these are better than oversimplified summary tables, which policy-makers tend to take at face value.

The US Commission on the
Future of Higher Education is considering creating a similar public database, which would News \& World Report. Bennett says he will work with such groups that use "professional standards of measurement". Declan Butler 